\title{
Establishment of human esophageal cancer xenograft model in immunocompetent mice and explorations of related immunological changes
}

Ruirui Hu

Jining Medical University

Hongmei Zhang

Jining Medical University

Yanzhen Bi

Capital Medical University

Xiaoying Yao

Jining Medical University

Guiyuan Jin

Jining Medical University

Quanyi Wang

Jining Medical University

Haixiang Wei

Jining Medical University

Yufen Qin

Jining Medical University

Hairong Zhang

Jining Medical University

Feng Hong ( $\square$ fenghong9508@163.com )

Jining Medical University

Research

Keywords: Esophageal cancer, Microcarrier, Animal model, Cellular immunity

Posted Date: April 29th, 2020

DOI: https://doi.org/10.21203/rs.3.rs-23847/v1

License: (c) (1) This work is licensed under a Creative Commons Attribution 4.0 International License.

Read Full License 


\section{Abstract}

\section{[Background]}

To combine the primary cells of human esophageal cancer with a new type of three dimensional (3D) microcarrier 6 , and then to inoculate the complex subcutaneously into immunocompetent mice. To establish a new animal xenograft tumor model of human esophageal cancer, and to explore the changes in the immune indicators of mice during tumor formation.

\section{[Methods]}

1. Isolate and extract the primary cells of human esophageal squamous cell carcinoma (SCC); mix them well with the 3D microcarriers and fully incubate them. Then, inoculate the complex into the armpits of immunocompetent mice, and record the tumor formation rate and the pathological characteristics of xenograft tumors. 2. Isolate cells in the blood, bone marrow, and spleen of the experimental mice and the control mice, and detect changes in $\mathrm{CD}^{+}, \mathrm{CD}^{+}, \mathrm{CD}^{+}$, myeloid-derived suppressor cells (MDSCs), and dendritic cells (DCs) by flow cytometry.

\section{[Results]}

The microcarrier 6-based model subcutaneously transplanted primary cells of human esophageal cancer, which further successfully grew into xenograft tumors in immunocompetent mice; the tumor formation rate was $80 \%$. The hematoxylin-eosin ( $\mathrm{HE}$ ) staining and immunohistochemistry $(\mathrm{IHC})$ characteristics indicated consistencies with the human esophageal cancer cells. The flow cytometry analysis showed that $\mathrm{CD}^{+}$and $\mathrm{CD} 4^{+}$cells in the peripheral blood and bone marrow of the tumor-formed mice were significantly reduced $(P<0.05)$. The cell counts of MDSCs and DCs in the blood, bone marrow, and spleen were elevated as compared with the control group, and with the MDSCs increased the most dramatically and statistically significant increase $(P<0.05)$.

\section{[Conclusion]}

The new type of 3D microcarriers were combined with human esophageal SCC cells; this model could be used to successfully construct an immunocompetent mouse xenograft model of human esophageal cancer. We further found that during tumor formation, the tumor cells may inhibit cellular immunity by regulating MDSCs, leading to tumor immunity escape and promoting tumor development.

\section{Background}

Esophageal cancer is a malignant tumor that occurs in the basal cells of esophageal mucosa. In the early stage, esophageal cancer has non-specific symptoms; therefore, most patients are diagnosed in the middle and advanced stages of esophageal cancer. Hence, the prognosis is poor in most cases. Currently, the mechanisms of occurrence and the development of esophageal cancer has not been elaborated extensively in research studies; moreover, the tumor immunology of esophageal cancer is not understood 
clearly till date. Presently, animal models that completely mimic human diseases are established to dynamically reveal the mechanism of tumorigenesis at the overall level; moreover, these animal models are further used in devising strategies for the prevention and treatment of diseases [1-2]. In this study, a cell culture was prepared by using primary cells of human esophageal squamous cell carcinoma (SCC); these cells were cultured on the microcarrier 6 to establish an animal model of subcutaneous xenograft tumor in immunocompetent mice. During the formation of tumor, researchers detected changes in the immune cells of the blood, bone marrow, and spleen of mice. The modeling method was used to establish an immunocompetent mouse model of esophageal cancer and to elucidate the internal connections between the occurrence and development of esophageal cancer and the body's main immune cells, thereby providing a new pathway for the immune mechanism study of tumor formation.

\section{Materials And Methods}

\subsection{Experiment animals}

A total of 40 C57BL/ 6 male mice that were eight weeks old, were purchased from Jinan Pengyue Experimental Animal Breeding Co., Ltd.(license number: SCXK 20140007, Shandong Province, China) These mice were raised at the specific pathogen-free (SPF)-level in the Experimental Animal Center of the Affiliated Hospital of Jining Medical College, Jining City, Shandong Province, China. All the animal experiments were conducted in compliance with the relevant regulations of the Animal Ethics Committee of the Affiliated Hospital of Jining Medical College

\subsection{Esophageal Cancer Specimens}

The surgical specimens of esophageal cancer were obtained from the Department of Thoracic Surgery, Affiliated Hospital of Jining Medical College, Jining City, Shandong Province, China. Prior to the study, all participants signed informed consent letters. Furthermore, the study protocol was approved by the Clinical Study Evaluation Committee of the Affiliated Hospital of Jining Medical College. This study was conducted in compliance with the relevant regulations of the Ethics Committee of Affiliated Hospital of Jining Medical College. The general patient information was presented in Table 1. 
Table 1

General information of the esophageal cancer patients.

\begin{tabular}{|c|c|c|c|c|c|c|}
\hline Patient & Gender & Age & $\begin{array}{l}\text { Preoperative Imaging } \\
\text { Evaluation for } \\
\text { Metastasis }\end{array}$ & $\begin{array}{l}\text { Specimen } \\
\text { Size }\end{array}$ & $\begin{array}{l}\text { Postoperative } \\
\text { Pathology }\end{array}$ & $\begin{array}{l}\text { Postoperative } \\
\text { Lymph Nodes } \\
\text { Examination for } \\
\text { Metastasis }\end{array}$ \\
\hline 1 & Male & 53 & None & $\begin{array}{r}5.0 \times 4.5 \\
\times 1.7 \mathrm{~cm}\end{array}$ & $\begin{array}{l}\text { Well- } \\
\text { differentiated } \\
\text { medullary } \\
\text { SCC }\end{array}$ & $\begin{array}{l}\text { Local paracardia } \\
\text { lymph node } \\
\text { metastasis }\end{array}$ \\
\hline 2 & Female & 64 & $\begin{array}{l}\text { Swelling of } \\
\text { mediastinal lymph } \\
\text { node, metastasis not } \\
\text { rule out }\end{array}$ & $\begin{array}{l}3.0 \times 3.0 \\
\times 2.5 \mathrm{~cm}\end{array}$ & $\begin{array}{l}\text { Poorly } \\
\text { differentiated } \\
\text { SCC }\end{array}$ & $\begin{array}{l}\text { Paraesophageal } \\
\text { lymph node } \\
\text { metastasis }\end{array}$ \\
\hline 3 & Female & 56 & None & $\begin{array}{l}2.7 \times 2.4 \\
\times 1.5 \mathrm{~cm}\end{array}$ & $\begin{array}{l}\text { Well- } \\
\text { differentiated } \\
\text { SCC }\end{array}$ & None \\
\hline 4 & Male & 68 & $\begin{array}{l}\text { Local mediastinal } \\
\text { lymph node } \\
\text { metastasis }\end{array}$ & $\begin{array}{l}5.4 \times 3.5 \\
\times 1.4 \mathrm{~cm}\end{array}$ & $\begin{array}{l}\text { Moderately- } \\
\text { differentiated } \\
\text { medullary } \\
\text { SCC }\end{array}$ & $\begin{array}{l}\text { Subcarinal } \\
\text { lymph node } \\
\text { metastasis }\end{array}$ \\
\hline
\end{tabular}

\subsection{Microcarrier}

Microcarrier 6 was purchased from Elyon Biotechnologies LLC. (Gaithersburg, MD, USA). This is a new type of microcarrier ; it is composed of organic composite polymers showing positive polymerization; moreover, it has a multi-layered pore structure. The microcarrier 6 has advantages of low immunogenicity, good biocompatibility, and metabolizable structure. Thus, it provides a stable microenvironment for cell growth.

\subsection{Main Reagents}

Dulbecco's modified Eagle medium (DMEM), collagenase B, fetal bovine serum, ammonium chloridepotassium (ACK) lysing buffer, phosphate-buffered saline (PBS), and penicillin were purchased from Gibco, (Thermo Fisher Scientific, Waltham, MA,USA). The mouse monoclonal antibodies against human p40 and Cytokeratin (CK) 5/6 were purchased from Wuxi Dong Yuan Biotech, Inc(Jiang Su Province,China),

\subsection{Isolation and extraction of primary cells of human esophageal cancer}

The specimens of esophageal cancer were surgically extracted and placed in a sterile solution of physiological saline. After half an hour, they were sent to the laboratory for treatment. First, the superficial blood and debris were removed from the specimens by rinsing them thrice in serum-free DMEM. Then, 
they were cut mechanically with a tissue scissor. Thereafter, the specimens were placed in $0.05 \%$ collagenase $\mathrm{B}$ and digested in an incubator at $37^{\circ} \mathrm{C}$. The tissue digestion process was checked every $30 \mathrm{~min}$ to $1 \mathrm{~h}$, and samples were repeatedly pipetted from the medium. After one hour, serum-free DMEM was added to dilute the medium and to mix the tissue samples by pipetting. After centrifuging the medium at $400 \mathrm{r} / \mathrm{min}$ for $10 \mathrm{~min}$, the supernatant was removed and the precipitate was added to collagenase $B$ for further digestion. The removed supernatant was then added to DMEM to terminate the digestion. Then, it was filtered with a $70 \mu \mathrm{m}$ filter and centrifuged at $1200 \mathrm{r} / \mathrm{min}$ for $8 \mathrm{~min}$. Thereafter, the supernatant was discarded, and the precipitate was added to ACK lysing buffer. After 5 min, DMEM was added to dilute the solution, and the sample was then centrifuged at $1000 \mathrm{r} / \mathrm{min}$ for $8 \mathrm{~min}$ to extract the first batch of esophageal cancer cells. Furthermore, the above steps were repeated to extract the remaining batches of esophageal cancer cells with a digestion time of $2 \mathrm{~h}$ and $3 \mathrm{~h}$, respectively.

\subsection{Establishment Of Three-dimensional (3D) Cell Culture Model}

The microcarrier 6 was soaked in $75 \%$ alcohol for $24 \mathrm{~h}$, and then rinsed three times with $1 \times$ PBS, followed by incubation in DMEM for $24 \mathrm{~h}$. The microcarrier was modified using $100 \mathrm{ng} / \mathrm{mL}$ stromal cell derived factor-1a (SDF-1a) and $100 \mathrm{ng} / \mathrm{mL}$ vascular endothelial growth factor (VEGF), with an incubation time of $3 \mathrm{~h}$. The extracted esophageal cancer cells were placed in DMEM, which contained $10 \%$ fetal bovine serum and $1 \%$ penicillin, and the extract was then pipetted into a single-cell suspension. The microcarrier was added to the single-cell suspension and the ratio of cell to carrier volume was maintained at about

3:1 (cell count of the suspension: $\sim 2 \times 10^{7} / \mathrm{ml}$, and microcarrier: $\sim 300 \mu \mathrm{g} / \mathrm{ml}$ ), and then it was placed in a $5 \% \mathrm{CO}_{2}$ incubator for $24 \mathrm{~h}$. The temperature of the incubator was maintained at $37^{\circ} \mathrm{C}$.

\subsection{Preparation Of Animal Model And The Observation Indicators}

For the patient-derived xenotransplantation (PDX) group, the esophageal cancer cell-microcarrier complexes were inoculated into the right armpits of immunocompetent mice, with a dose of $100 \mu \mathrm{l} /$ mouse; the control group was inoculated with an equal amount of microcarrier only. A total of four experiments were performed with five mice in each group. After inoculation, we observed the mental state, activity, and diet of the experimental mice; moreover, the time of local tumor occurrence and the tumor volume were recorded too. After the formation of tumor, the long diameter (a) and short diameter (b) of the tumor were measured every day, and the tumor volume was calculated according to the equation $V=$ $1 / 2 \times a \times b^{\wedge} 2$. Fourteen days later, the PDX mice were euthanized by cervical dislocation (CD). The tumor tissues were extracted completely, and the tumor volume, texture, and the degree of necrosis were recorded. The tumor tissue was fixed with $10 \%$ neutral formalin, and it was then sent to the pathology department for hematoxylin-eosin (HE) staining and immunohistochemical (IHC) staining. 


\subsection{Flow Cytometry}

To perform flow cytometry, the fluorescence-conjugated antibodies against the myeloid-derived suppressor cells (MDSCs, defined as CD11 $\mathrm{b}^{+} \mathrm{Gr}-1^{+}$cells), dendritic cells (DCs, defined as $\mathrm{CD} 11 \mathrm{c}^{+}$cells), and CD3, CD4, and CD8 markers were purchased from eBioscience (San Diego, CA, USA), and they were used at a dilution of 1:100. After euthanizing the mice, we prepared the blood, liver, and spleen cell suspensions. The cell phenotype staining samples were rinsed twice with PBS, which contained $1 \%$ fetal bovine serum and $0.1 \% \mathrm{NaN}_{3}$. Standard procedures were used to incubate cells with the following antimouse antibodies at $4{ }^{\circ} \mathrm{C}$ for 30 minutes: CD11b-fluorescein isothiocyanate (FITC), Gr-1-algaphyrin (APC), CD3-FITC, and CD8a-phycocyanin protein (PE), CD4-APC, CD11c-PE, Ly6G-APC, and Ly6c-PE. After being washed twice with PBS, the cells were analyzed with FACSCalibur (Becton Dickinson, San Jose, CA, USA). The isotype control was performed for each antibody.

\subsection{Statistical Analysis}

The SPSS 13.0 software (IBM, Armonk, New York, USA) was used for statistical analysis. The measurement data was presented as $\mathrm{x} \pm \mathrm{s}$, and the independent sample $t$ test was used for the comparison of between-groups. $\mathrm{P}<0.05$ was considered as statistically significant.

\section{Results}

\subsection{General conditions of mice after inoculation}

Within 2-3 days after inoculation, the condition of the mice was as follows: reduced appetite, decreased activity, and poor mental state; however, not a single mouse died during this process.

\subsection{Tumor formation time, tumor volume, and tumor formation rate}

The xenograft tumor began to grow in about 8-10 days, and it reached the peak value of growth in about 12-16 days. The formed tumors had a diameter of $0.6-1.0 \mathrm{~cm}$. These tumors were mostly round or oval in shape; they had a tough or hard texture and a grayish-white cut surface. The rate of tumor formation was $80 \%$.

\subsection{HE Staining}

The xenograft tumor tissue displayed heterogeneous cells. These cells were of various sizes, and they exhibited a disordered arrangement under a microscope. In general, most cells were oval in shape; these cells had large and varied nuclei, coarse chromatin, obvious nucleoli, and a clearly visible nuclear division. Large necrosis was observed in the center of the tumor, and capillaries were visibly distributed around the tumor. 


\subsection{IHC Detection}

According to the $\mathrm{IHC}$ results, the expression of $\mathrm{p} 40$ and CK $5 / 6$ cells was found to be positive. This confirms that atypical cells were actually human-derived esophageal cancer cells.

\subsection{Flow Cytometry}

Peripheral blood of the PDX group was compared with the control group. It was found that the PDX group showed significantly reduced expression of $C D 3^{+}$and $C D 4^{+}$cells $(P=0.0071$ and $P=0.0325$, respectively) and a slightly increased expression of $\mathrm{CD} 8^{+}$cells as compared to the control group. In the PDX group, the total MDSCs and granulocytic MDSCs (G-MDSCs) were significantly increased ( $P<0.0001$ for both); however, the monocytic MDSCs (M-MDSCs) were decreased in the PDX group as compared to that in the control group. The DCs of the PDX group were significantly more than that in the control group $(P=$ 0.002). (Fig. 4-8)

The bone marrow of the PDX group was compared with the control group. It was found that the PDX group had decreased $\mathrm{CD}^{+}, \mathrm{CD}^{+}$, and $\mathrm{CD}^{+}$cells as compared to those in the control group, with $\mathrm{CD}^{+}$ cells showing the least expression and statistically significantly reduced activity $(P=0.0126)$, followed by CD8 ${ }^{+}$cells' statistically reduced expression $(P=0.0712)$. The total, $G-$ and M-MDSCs were all increased in the PDX group as compared to those in the control group, with the total MDSCs being the highest in number $(P=0.0009)$. The $D C s$ of the PDX group were slightly increased as compared with the control group, but not significantly increased statistically $(p=0.2307)$. (Fig. 4-8)

Finally, the spleen tissue of the PDX group was compared with the control group. It was found that the PDX group had a decreased expression of $\mathrm{CD}^{+}, \mathrm{CD}^{+}$, and $\mathrm{CD} 8^{+}$cells as compared to the control group, with $\mathrm{CD}^{+}$cells' expression being the most reduced and also significantly reduced statistically $(\mathrm{P}=$ 0.0139). The $C D 3^{+}$and $C D 8^{+}$cells dropped too, but the dropped values were not statistically significant $(P=0.0525$ and $P=0.0961$, respectively). The total, $G$ - and M-MDSCs of the PDX group were all increased as compared to the control group, with the G-MDSC expression being the most increased value $(P=$ 0.0082). The DCs of the PDX group were also increased as compared with that of the control group ( $p=$ 0.0433). (Fig. 4-8)

\section{Discussion}

Esophageal cancer is one of the most common malignant tumors of the digestive tract, and its pathogenesis is not fully understood till date. Therefore, the morbidity and mortality of patients with esophageal cancer continues to be high even today. Moreover, the prognosis is poor in patients diagnosed at an advanced stage [3-4]. For a long time, human tumor cell lines and xenograft nudemouse models have been used as the primary platform for tumor research and new anti-cancer drug development. However, tumor tissues that are formed by cell lines lack interstitial cells, which play an 
important role in the development and metastasis of tumor [5]; therefore it is difficult to accurately simulate the true conditions of clinical patients [6]. In recent years, international scholars have transplanted fresh surgical tumor specimens from patients to immunodeficient mice. Thus, they have established a new animal model called patient-derived xenografts (PDXs). These models can successfully represent the biological, histological, and pathological characteristics of the patients' tumors at the molecular level.

On this basis, our study devised a new type of 3D microcarrier, namely, the microcarrier 6 , to co-incubate the primary cells of human esophageal cancer and to construct a 3D growth known as "tumor organoid." Thus, this study established a patient-derived xenograft (PDX) tumor model in immunocompetent mice. This model overcame the major shortcoming of immunodeficient mouse model, which could not accurately simulate the immune attack on tumors by the immune system because it lacked immune cells (especially the T lymphocytes). Thus, the immunocompetent model of the present study can more accurately represent the biological and histological characteristics of tumor tissues and tumor microenvironment at the molecular level.

By only inoculating the primary human esophageal cancer cells in mice, we could not form a normal xenograft tumor because of xenograft rejection. However, the 3D tumor cell culture system could simulate the tumor growth microenvironment and has become a hotspot of current research [7-10]. This study used a new type of 3D microcarrier, the microcarrier 6 , which has a loose texture and a multi-layered pore structure. Thus, microcarrier 6 favors the growth of tumor cells. After being modified by VEGF and SDF$1 \mathrm{a}$, the microcarrier 6 could also induce blood vessel growth and provide nutrition for the rapid growth of tumor.

The results of this experiment indicate that an $80 \%$ tumor formation rate could be achieved in the immunocompetent mouse xenograft model because it was based on microcarrier 6-human esophageal SCC primary cell complex. This model was characterized by rapid tumor formation, good reproducibility, and a relatively simple operation. The experiments proved that the xenograft tumor could be formed in 810 days and it reached its growth peak at days 12-16. The pathological HE staining results showed that the tumor cells grew too fast and formed a large number of necrotic lesions in the center of the tumor due to an insufficient blood supply. Capillaries were seen distributed around the tumor. All these results were in complete agreement with the characteristics of human tumor growth. The IHC detection results showed positive expressions of p40 and CK 5/6 cells. This further confirms that atypical cells had originated from human esophageal cancer cells. In the early stage of the experiment, our experimental team used this modeling method to construct a human gastric cancer transplant tumor model, and also achieved certain results [11].

As is well known, tumor cell immunity is closely related to the occurrence, development, and prognosis of tumors. The T lymphocytes are the most crucial function cells in the human body's immune system.. The investigation of changes in subsets and functions of T cells in the occurrence and development of tumor is helpful to reveal the mechanisms of tumorigenesis,which play a pivotal role in the occurrence and 
development of tumor .In this experiment, changes in the T cell subsets of $\mathrm{CD} 3^{+}, \mathrm{CD} 4^{+}$, and $\mathrm{CD} 8^{+}$were measured. The results indicate that in the bone marrow and spleen, the PDX group had fewer $\mathrm{CD} 3^{+}, \mathrm{CD}^{+}$, and $\mathrm{CD}^{+}$cells than in the control group. In the bone marrow, the $\mathrm{CD}^{+}$cells declined the most and the decline was statistically significant $(P=0.0126)$. In spleen tissues, $C D 4^{+}$cells decreased most significantly $(P=0.0139)$, and $C D 3^{+}$and $C D 8^{+}$also dropped to some extent $(P=0.0525$ and $P=0.0961$, respectively). Compared with the control group, the $\mathrm{CD} 3^{+}$and $\mathrm{CD} 4^{+}$cells in the peripheral blood of the PDX group were reduced significantly $\left(P=0.0071\right.$ and $P=0.0325$, respectively), but the change in $C D 8^{+}$ cells have a mild rise. We believe that if the sample size increases, the value will also show a downward trend. A clinical study [12] showed that in the peripheral blood of patients with esophageal cancer, CD $3^{+}$ and $\mathrm{CD} 4^{+}$cells were significantly reduced before surgery; however, their expression were significantly enhanced after surgery $(P<0.05)$. This indicates that in esophageal cancer patients who underwent radical operation, the cell immunosuppression ability was improved significantly. This change was in complete agreement with the $\mathrm{CD}^{+}$and $\mathrm{CD} 4^{+}$changes in our xenograft model, suggesting a suppressed cell immune function in the esophageal cancer xenograft model during tumor formation.

In the current experimental study, MDSCs are a heterogeneous group of cells that originate from the myeloid tissue at various stages of differentiation. These cells play an essential role in tumor-related immunosuppression.Moreover, MDSCs mediate the immune escape of tumors by suppressing the effector T cells and the natural killer (NK) cells. Based on the differential expression of CD11b and the lymphocyte antigen 6 complex (locus G, Ly6g, and Gr-1) on the cell surface of mice, the MDSCs could be divided into two independent groups, namely, the $\mathrm{CD} 11 \mathrm{~b}^{+} \mathrm{Ly} 6 \mathrm{C}^{\text {low }} \mathrm{Ly}_{6 \mathrm{G}} \mathrm{G}^{+}$granulocytic group, and the CD11 b ${ }^{+}$Ly6 $\mathrm{C}^{+} \mathrm{Ly}_{6 \mathrm{G}^{-}}$monocytic group. Nowadays they have become a hotspot in studies related to tumor immunity and autoimmunity because of their significant immunosuppressive functions [13-15]. In this study, the total MDSCs and their subtypes (G-MDSCs and M-MDSCs) were tested, and the antigenpresenting cells, DCs, were studied as well. The total MDSCs and G-MDSCs in the peripheral blood of the PDX group were found to be significantly increased as compared to those in the control group (both with $P<0.0001)$, and the DCs were significantly elevated in the PDX group too $(P=0.002)$. The total, $G-$ and $M-$ MDSCs in the bone marrow of the PDX group were all enhanced as compared with the control group; moreover, the total MDSCs increased particularly significantly $(P=0.0009)$. Furthermore, the DCs of the PDX group were slightly increased, but the increase was just not statistically significant $(P=0.2307)$. In the spleen, the total, G- and M-MDSCs of the PDX group were all increased compared to the control group, with the G-MDSCs being the most increased group of cells and the increase being statistically significant $(P=0.0082)$. The $D C s$ were also increased compared with the control group $(P=0.0433)$. The above changes in immune cells indicate that the esophageal cancer xenograft model can recruit more MDSCs and DCs in vivo during the occurrence and development of tumor. This indicates that MDSCs played an important role in the early stages of tumor development, and the tumor cells can further suppress the body's cellular immunity by mediating or regulating MDSCs and achieve immune escape. Presumably, this could be one of the essential mechanisms in the development of esophageal cancer. 
Due to the heterogeneity of MDSCs, the interactions among MDSCs, T cell subtypes, and DCs and the mechanisms of these interactions have not yet thoroughly understood till date. Therefore, the present model provided a better platform for further exploring the occurrence and development of tumors and their interactions with the body's immune cells.

\section{Conclusions}

In summary, the present study established a new animal model of esophageal cancer. This model was based on microcarriers, and it was used to investigate the changes in related immune cells. Some of the changes in immune cells were in complete agreement with the results of previous clinical research studies. This modeling method provided a new idea for establishing animal models for translational medicine and could be further explored and expanded in future studies.

\section{List Of Abbreviations}

squamous cell carcinoma (SCC);myeloid-derived suppressor cells (MDSCs);dendritic cells (DCs); granulocytic MDSCs (G-MDSCs);monocytic MDSCs (M-MDSCs); hematoxylin-eosin (HE); immunohistochemistry (IHC); Dulbecco's modified Eagle medium (DMEM), ammonium chloridepotassium (ACK) ,phosphate-buffered saline (PBS);patient-derived xenotransplantation (PDX);

\section{Declarations}

\section{- Ethics approval and consent to participate}

All the animal experiments were conducted in compliance with the relevant regulations of the Animal Ethics Committee of the Affiliated Hospital of Jining Medical College.

The surgical specimens of esophageal cancer were obtained from the Department of Thoracic Surgery, Affiliated Hospital of Jining Medical College, Jining City, Shandong Province, China. Prior to the study, all participants signed informed consent letters. Furthermore, the study protocol was approved by the Clinical Study Evaluation Committee of the Affiliated Hospital of Jining Medical College. This study was conducted in compliance with the relevant regulations of the Ethics Committee of Affiliated Hospital of Jining Medical College.

\section{- Consent for publication}

Not applicable

\section{- Availability of data and materials}

Not applicable

\section{- Competing interests}


The authors declare that they have no competing interests.

\section{- Funding}

This study was supported by grant from National Natural Science Foundation of China (81170395, 81570556)

\section{- Authors' contributions}

$\mathrm{RRH}$ coordinated the whole process of the experiment, responsible for collecting samples, isolating and extracting primary cancer cells, analyzing the experimental results and writing papers. He was the main first author.

FH was the main project designer, evaluated the experimental quality, participated in the modification of the paper, and was the corresponding author.

$\mathrm{HMZ}$ is responsible for data statistics and paper revision, and is the second author.

YZB has an important contribution to cell separation and extraction.

XYYand GYJ participated in flow cytometry detection and data analysis.

QYW participated in pathological examination and analysis.

HXW provides surgical specimens.

YFQ and HRZ participated in the modification of the paper.

All authors read and approved the final manuscript.

\section{- Acknowledgements}

Not applicable

\section{- Authors' information (optional)}

Not applicable

\section{References}

1. Domper Arnal MJ, Ferrández Arenas Á, Lanas Arbeloa Á. Esophageal cancer: Risk factors, screening and endoscopic treatment in Western and Eastern countries. World J [2] Gastroenterol. 2015;21(26):7933-43.

2. Liu DS, Duong CP, Phillips WA, Clemons NJ. Preclinical models of esophageal adenocarcinoma for drug development. Discov Med. 2016;22(123):371-9. 
3. Siegel RL, Jemal A, Wender RC, Gansler T, Ma J, Brawley OW. An assessment of progress in cancer control. CA Cancer J Clin. 2018;68(5):329-39.

4. Siegel RL, Miller KD, Jemal A. Cancer statistics, 2019. CA Cancer J Clin. 2019;69(1):7-34.

5. Bhowmick NA, Neilson EG, Moses HL. Stromal fibroblasts in cancer initiation and progression[J]. Nature. 2004;432(7015):332-7.

6. Kopetz S, Lemos R, Powis G. The promise of patientderived xenografts: the best laid plans of mice and men[J]. Clin Cancer Res. 2012;18(19):5160-2ãष区.

7. Jaeger S, Duran- Frigola M, Aloy P. Drug sensitivity in cancer cell lines is not tissue-specific[J]. Mole Cancer. 2015;14(40):2-4.

8. Mitra A, Mishra L, Li S. Technologies for deriving primary tumor cells for use in personalized cancer therapy[J]. Trends Biotechnol. 2013;31(6):347-54.

9. Rimann M, Graf-Hausner U. Synthetic 3D multicellular systems for drug development[J]. Curr Opin Biotechnol. 2012;23(5):803-9.

10. Adcock AF, Trivedi G, Edmondson R, et al. Three-dimensional (3D) cell cultures in cell-based assays for in-vitro evaluation of anticancer drugs[J]. J Anal Bioanal Tech. 2015;6(3):247.

11. Bi YZ, Wang QY, Yang YH, et al.Establishment of a Human Gastric Cancer Xenograft Model in Immunocompetent Mice Using the Microcarrier-6.BioMed Research international,2020,2020:1893434.

12. Wang JY, Dai SQ, Ye WF, Long H, Lin P, Li BJ, Rong TH. Perioperative changes of cellular immune response of patients with esophageal carcinoma evaluated through detecting AgNOR content in peripheral blood T lymphocytes and T cell subsets. Ai Zheng. 2005;24(7):861-4.

13. Gabrilovich DI. Myeloid-Derived Suppressor Cells. Cancer Immunol Res. 2017;5(1):3-8.

14. Veglia F, Perego M, Gabrilovich D. Myeloid-derived suppressor cells coming of age. Nat Immunol. 2018;19(2):108-19.

15. Tcyganov E, Mastio J, Chen E, Gabrilovich DI. Plasticity of myeloid-derived suppressor cells in cancer. Curr Opin Immunol. 2018;51:76-82.

\section{Figures}


A

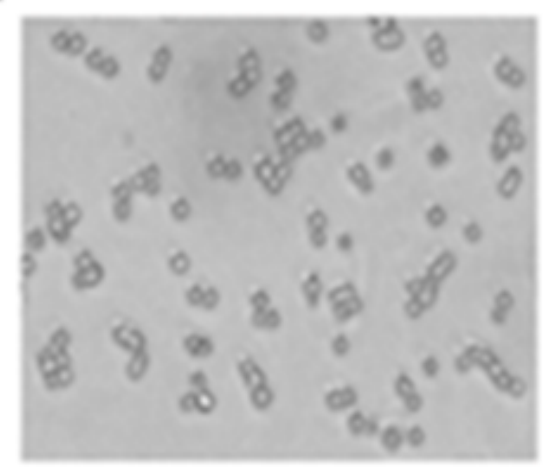

D

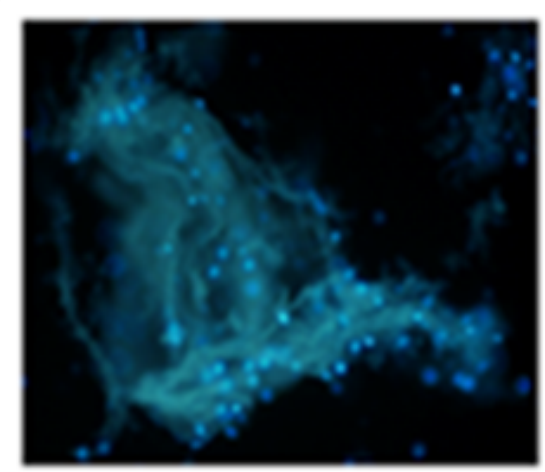

B

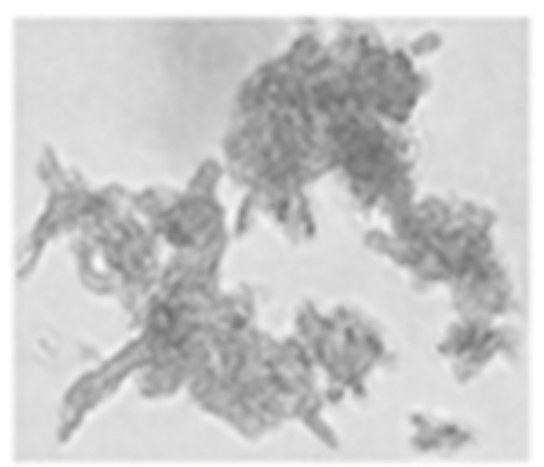

E

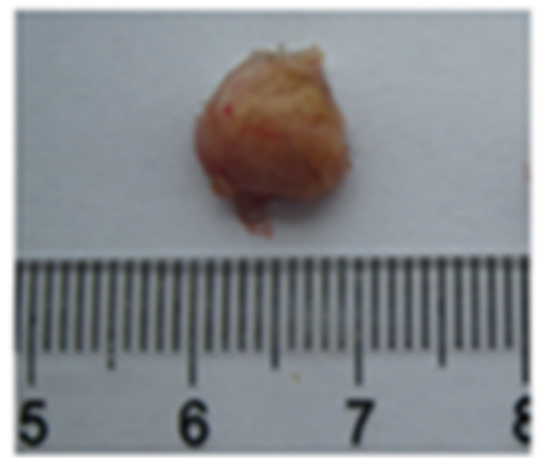

C

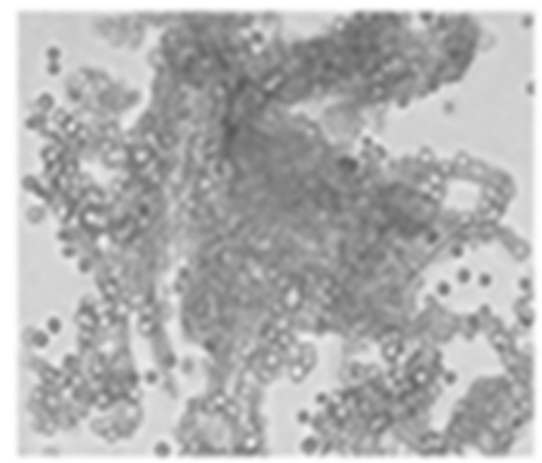

$\mathbf{F}$

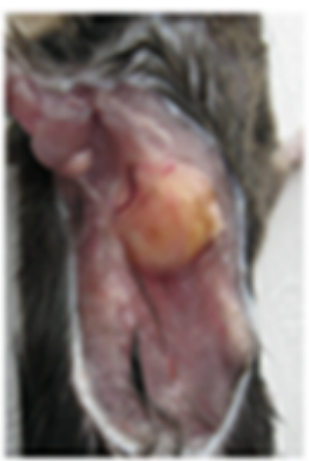

\section{Figure 1}

A: Isolated esophageal SCC cells. B: Microcarrier 6. C: Microcarriers and primary cells of esophageal cancer co-incubated for $24 \mathrm{~h}$. D: DAPI (4',6-diamidino-2-phenylindole) staining of cell-microcarrier complex (fluorescence-positive for tumor cells). E: Xenograft tumor. F: Animal model of human esophageal cancer. 


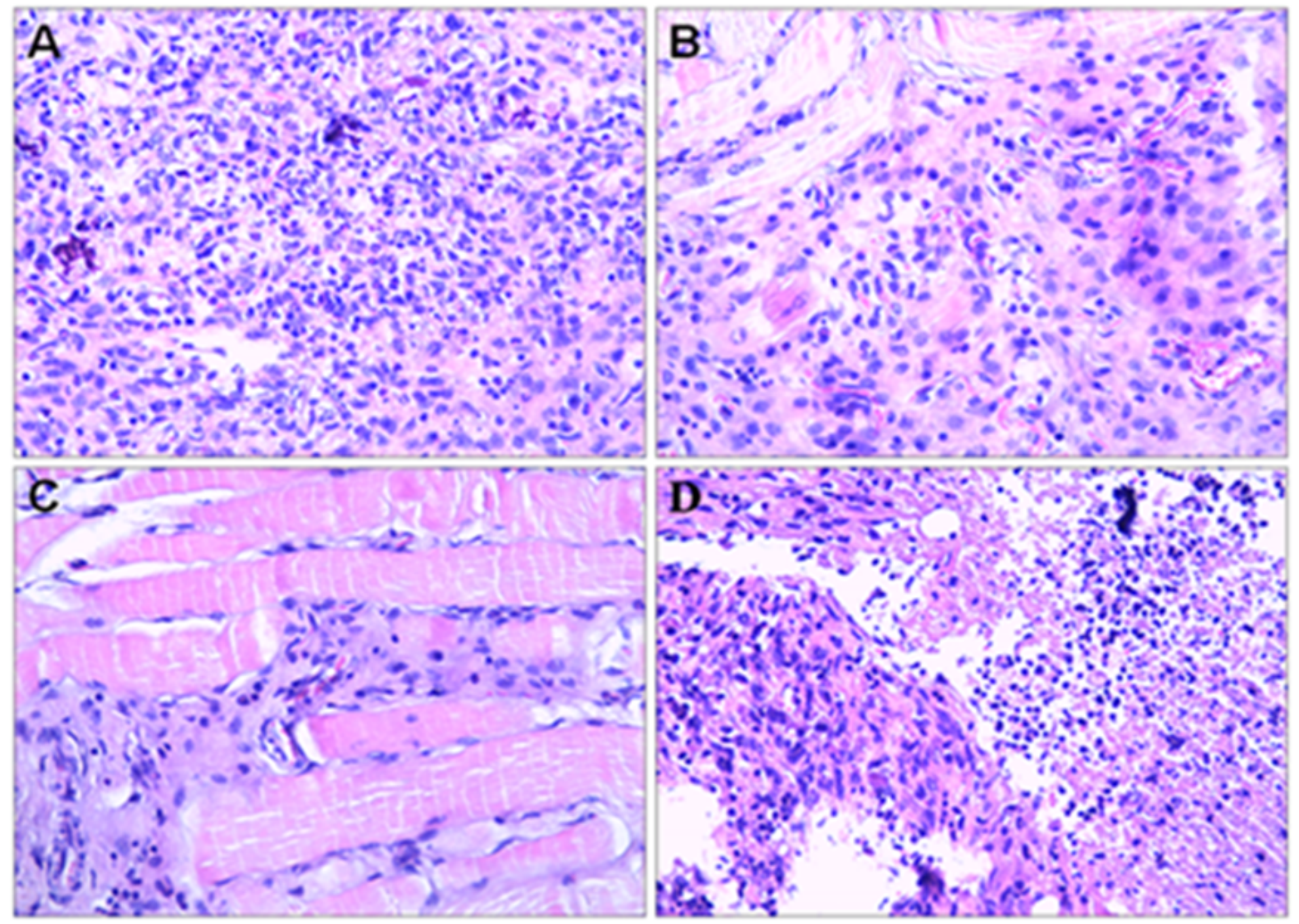

Figure 2

HE staining (×400). A. Deep-stained, heterogeneous atypical cells were seen under a microscope. B. Blood vessel formed around the tumor; C. Tumor cells infiltrating striated muscle; D. Massive necrosis around the tumor. 


\section{PDX-1 PDX-2}

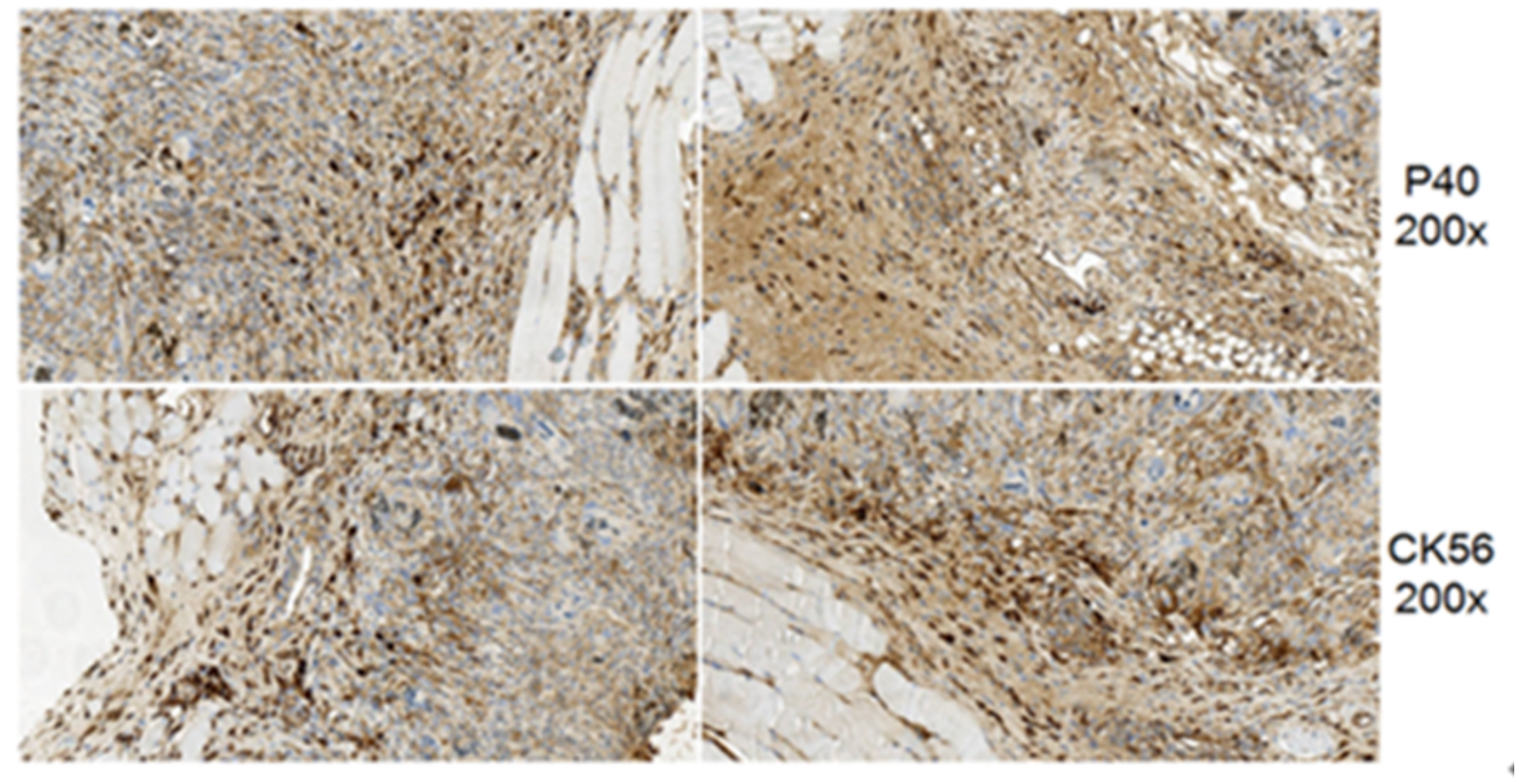

\section{Figure 3}

IHC staining $(\times 200)$ for P40 and CK 5/6. The cells with deep nuclear staining are tumor cells. 


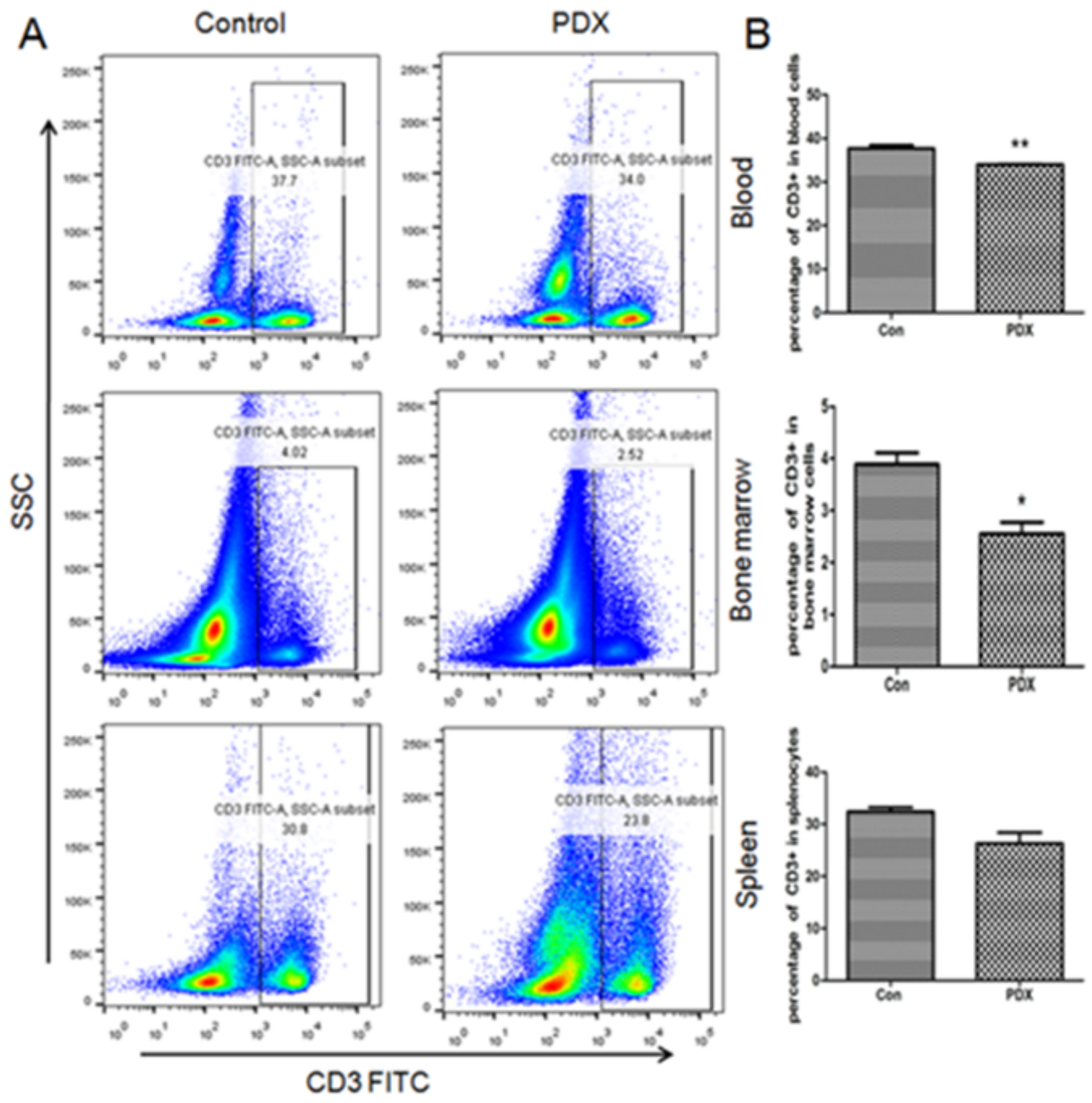

Figure 4

Changes of $\mathrm{CD} 3+$ in various tissues. Control (control group); PDX (tumor formation group). * $\mathrm{P}<0.05$, ** $P<0.01$, $\star \star \star ~ P<0.0001$. In peripheral blood, bone marrow, and spleen, the PDX group shows decreased $\mathrm{CD} 3+$ cells compared with the control group; the declines in peripheral blood and bone marrow are statistically significant. 


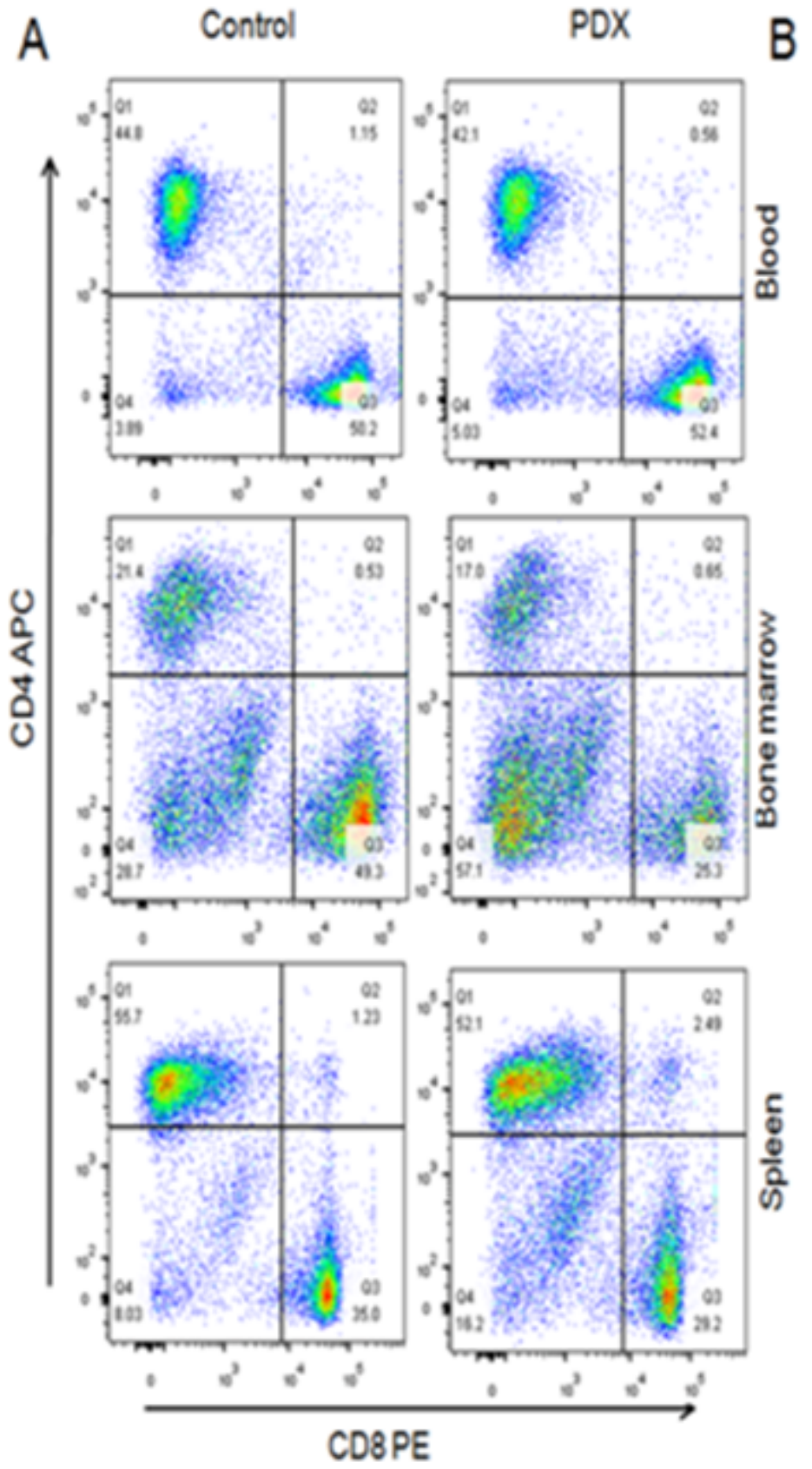

B
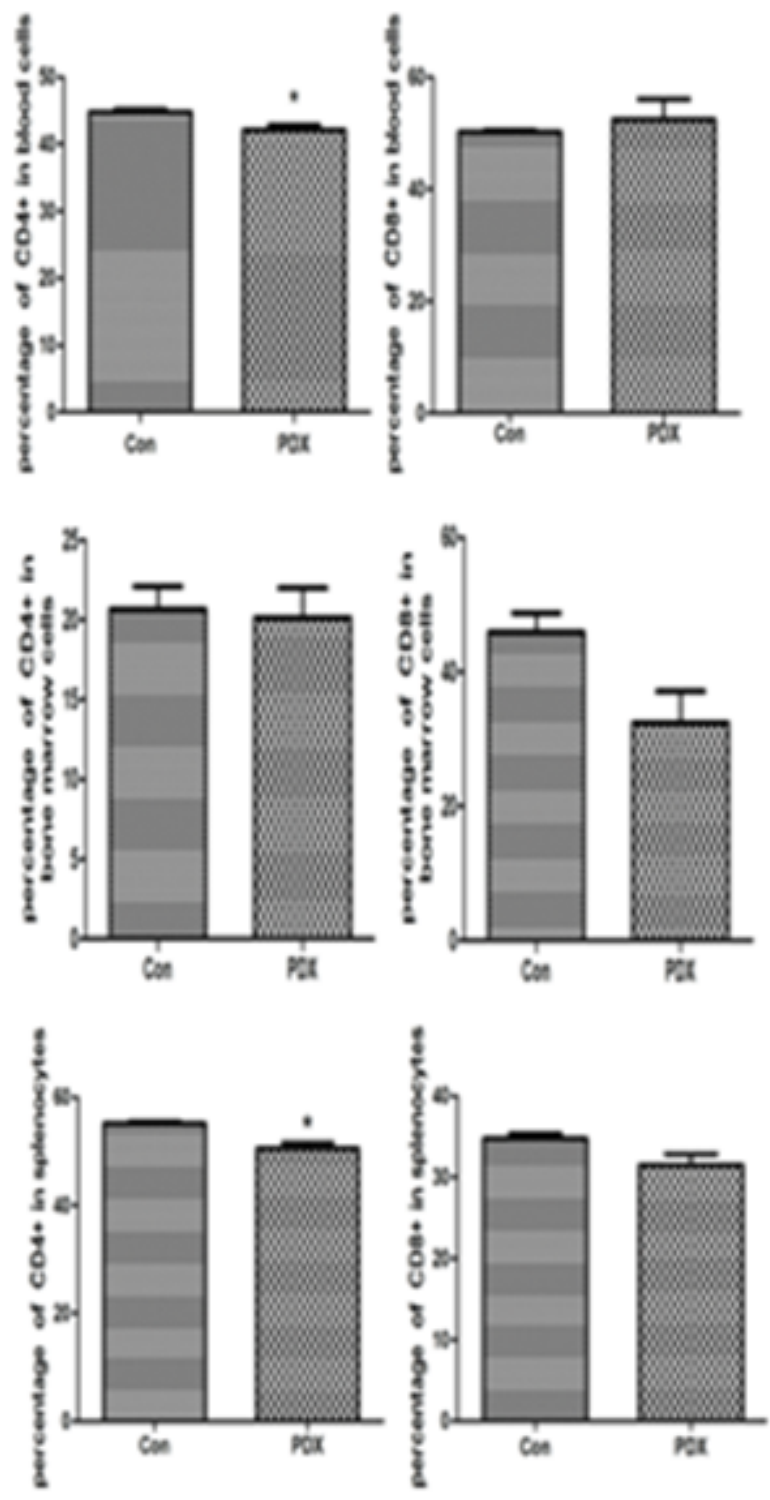

\section{Figure 5}

Changes of CD4+ in various tissues. Control (control group); PDX (tumor formation group). * $\mathrm{P}<0.05$, * $\mathrm{P}<0.01$, $\star \star \star \mathrm{P}<0.0001$. In peripheral blood, bone marrow, and spleen, the PDX group shows decreased CD4+ cells compared with the control group; the declines in peripheral blood and spleen are statistically significant $(P<0.05)$. Compared with the control group, the PDX group has slightly increased CD $8+$ cells in peripheral blood and decreased CD8+ cells in bone marrow and spleen. 



Figure 6

Changes of DCs in various tissues. Control (control group); PDX (tumor formation group). ${ }^{*} P<0.05$, ** $P$ $<0.01$, ${ }^{* \star *} \mathrm{P}<0.0001$. In peripheral blood, bone marrow, and spleen, the PDX group shows increased DCs compared with the control group; moreover, the increases in peripheral blood and spleen are statistically significant. 


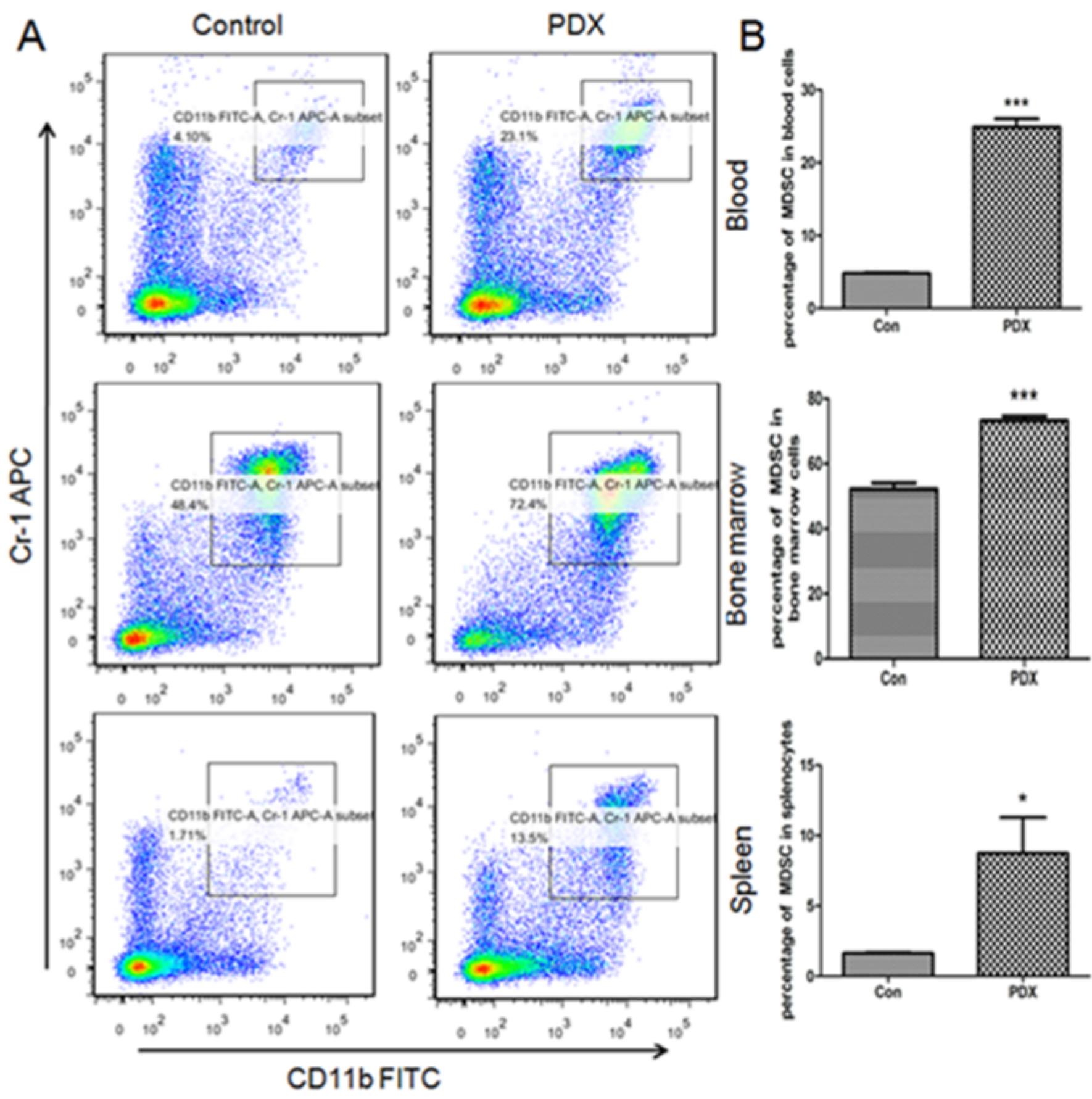

Figure 7

Changes of total MDSCs in various tissues. Control (control group); PDX (tumor formation group). * $\mathrm{P}<$ 0.05 , $* \star P<0.01, \star \star \star ~ P<0.0001$. In peripheral blood, bone marrow, and spleen, the PDX group shows statistically significant increase in MDSCs as compared with that of the control group; moreover, the increases in bone marrow and peripheral blood are the most significant $(P<0.0001)$. 


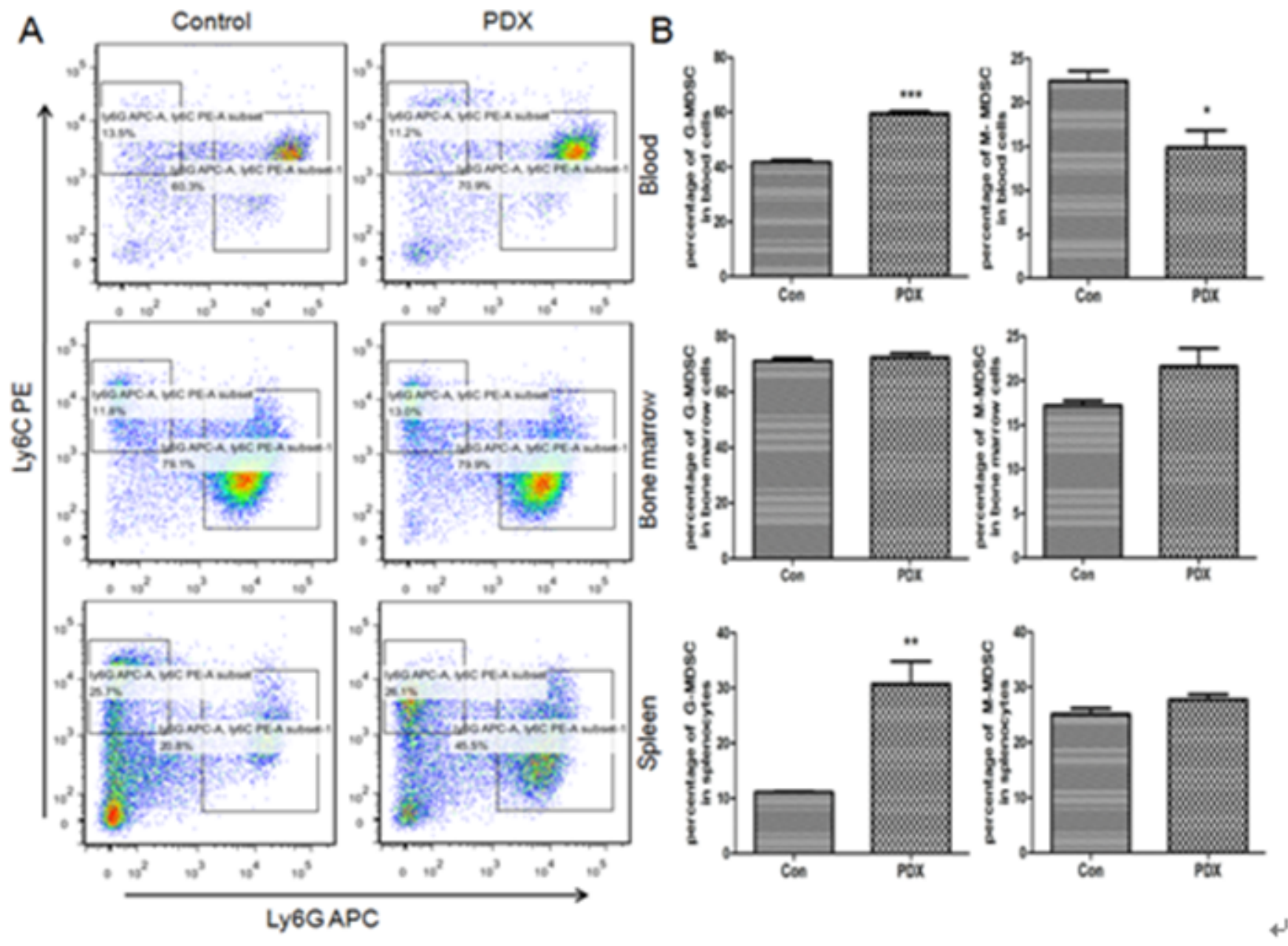

Figure 8

Changes of G- and M-MDSCs in various tissues. Control (control group); PDX (tumor formation group). * $P<0.05, * * P<0.01$, $* \star * P<0.0001$. The PDX group shows decreased MDSCs in peripheral blood and increased MDSCs in bone marrow and spleen as compared with those of the control group. The GMDSCs of the PDX group in the three tissues are all increased, with the increases in peripheral blood and spleen being statistically significant. 